Relations between teaching and research in physical geography and mathematics at research-intensive universities

Madsen, Lene Møller; Winsløw, Carl

Published in:

International Journal of Science and Mathematics Education

Publication date:

2009

Document version

Early version, also known as pre-print

Citation for published version (APA):

Madsen, L. M., \& Winsløw, C. (2009). Relations between teaching and research in physical geography and

mathematics at research-intensive universities. International Journal of Science and Mathematics Education, 7, 741-763. 
LENE MØLLER MADSEN AND CARL WINSLØW

\title{
RELATIONS BETWEEN TEACHING AND RESEARCH \\ IN PHYSICAL GEOGRAPHY AND MATHEMATICS AT RESEARCH-INTENSIVE UNIVERSITIES
}

\author{
Received: 18 June 2007; Accepted: 8 April 2008
}

\begin{abstract}
We examine the relationship between research and teaching practices as they are enacted by university professors in a research-intensive university. First we propose a theoretical model for the study of this relationship based on Chevallard's anthropological theory. This model is used to design and analyze an interview study with physical geographers and mathematicians at the University of Copenhagen. We found significant differences in how the respondents from the two disciplines assessed the relationship between research and teaching. Above all, while geography research practices are often and smoothly integrated into geography teaching even at the undergraduate level, teaching in mathematics may at best be 'similar' to mathematical research practice, at least at the undergraduate level. Finally, we discuss the educational implications of these findings.
\end{abstract}

KEY WORDS: didactics, mathematics, physical geography, teaching-research nexus

\section{INTRODUCTION}

Research is potentially important to university education in three main ways. Firstly, the contents and methods taught in university programs are typically 'closer' to contemporary research than the subjects taught in preuniversity education. Secondly, university teachers have direct experience with research and they are usually hired to do both research and teaching. Thirdly, the students may themselves become involved in research, at least at later points of their studies; in fact, graduate studies with the perspective of becoming a researcher are highly profiled options for them.

How do these conditions affect concrete teaching practices within research-intensive universities? Conversely, how do educational activities affect the scientific research done in these universities? These broad questions have been studied extensively and in many variations in the higher-education research literature, mainly concerning universities in general but also to a lesser degree concerning research-intensive universities (e.g., Elen, Lindblom-Ylänne, \& Clement 2007). However, most of these studies have been conducted at a general level, which does not consider actual activities of teaching and research, and in particular

(C) National Science Council, Taiwan (2008) 
not their subject matter specificities. In other terms, there seems to be little research on how the concrete interactions of teaching and research depend on the disciplines involved, in particular most studies consider either one or no specific disciplines of teaching and research. Moreover, we seem to lack a coherent model for research and teaching activity that would take into account subject matter specificity. In the section Background and Motivation, we give a short review of previous educational research on these issues, and we then proceed to our two main purposes:

- to present a coherent analytical model for studying the relationship between research and teaching activities related to a scientific discipline (see section Theoretical Framework)

- to use this model in a study of how five professors of mathematics and five professors of physical geography describe the relation between their research and their teaching, and in particular to articulate how this depends on the specificity of the discipline (mathematics/geography) involved (see the section Theoretical Framework).

In the conclusion (see section Conclusions), we return briefly to the general perspective: to what extent does the relationship between teaching and research depend on the discipline and what does this difference mean in terms of potentials and conditions for developing it?

\section{BACKGROUND AND Motivation}

We shall consider the questions outlined above in the context of universities with a strong focus on research, and where teaching and research co-exist in the sense that the same people do teaching and research. While this certainly includes the classical types of European universities (cf. Mora, 2001), the functioning and functions of universities have been rapidly changing in recent decades. There is a tendency of convergence towards universities as corporation-like 'service providers of the knowledge age' (ibid. p. 108). To these new knowledge corporations, both education and scientific research are crucial 'products' that are being marketed, sold, and frequently evaluated. We have several international rankings of universities, based primarily on more or less credible measures of their performance on research and education. On this background, it is not surprising that the relation between teaching and research gets renewed attention (see e.g., Brew, 1999). What can be made of Humboldt's ideal of 'Einheit von Lehre und Forschung' (unity of 
teaching and research) in corporate universities that compete for funding and students? Should teaching and research (continue to) coexist and be delivered by the same people? And if so, why?

In the higher-education research literature, the hypothesis of a general 'nexus' between teaching and research has been scrutinized in hundreds of papers (e.g., Elton, 2001; Ramsden \& Moses, 1992). Here the term nexus means a semantic connection of phenomena that influence each other in positive or negative ways. For instance, Neumann (1992) found 'a strong belief in a symbiotic nexus between teaching and research' among senior academic administrators in Australia, and identified three levels: (1) the tangible nexus, relating to the communication in teaching of the newest knowledge; (2) an intangible nexus, referring to effects on the working modes of teachers and students resulting from the fact that the teachers are also researchers; (3) a global nexus, where the connection is situated at the institutional rather than at the individual level.

A large number of studies have attempted to find evidence for positive or negative correlations of type (3), rather than just beliefs. In a seminal paper, Hattie \& Marsh (1996) examined a total of 58 studies from which they extracted a total of 498 correlation coefficients between measures of quality of research and teaching in institutions of education and research. The weighted average of these coefficients turned out to be within the total variation; after excluding outliers it was a mere .05 (p. 525). Hattie and Marsh concluded that 'the relationship between teaching and research is zero, and it would be more useful to investigate ways to increase the relationship' (p. 533). In fact, 10 years earlier, Elton (1986) stated that questions about a possible connection between teaching and research 'when put on a departmental or institutional scale cannot conceivably be answered through simplistic quantitative methods' (p. 300). After examining several classical approaches, he suggests that the relationship between teaching and research should be studied at a more local level: 'It is necessary to distinguish between three activities: teaching, scholarship, and research. It is then likely that at this [the individual, authors] level, teaching and research can fertilize each other, but only through the mediation of scholarship' (p. 303).

So if we are to go beyond superficial ideas about the nexus between teaching and research, we are led to consider it at the individual level ((1) and (2) above). Then the fruitful question is not whether teaching and research support each other automatically, but we must explore the nature of and conditions for a positive nexus between teaching and research within a discipline. To do so in a systematic way, we need a theoretical model to describe, in a coherent way, the pertinent aspects of research and teaching. 


\section{THEORETICAL Framework}

Our aim is to model the interplay between university teaching and research within a scientific discipline, in order to be able to design and analyze a study of how professors describe these activities. For this purpose, we have found it useful to adopt and adapt the so-called 4T-model from the anthropological theory of didactics (cf. Chevallard, 1999; Barbé, Bosch, Espinoza, \& Gascón, 2005). To keep this paper reasonably self-contained, we explain the basic elements of this model and our adaptation of it in the subsection Praxeologies and Praxeological Organizations. Then, in subsection Model of the Interplay Between Teaching and Research, we present our general proposal for a model to study the interplay.

\section{Praxeologies and Praxeological Organizations}

The development of educational theory is inseparable from the classical epistemological debates around the delimitations and roles of human action, reasoning, and discourse in the processes of learning and developing human knowledge. In the 20th century, various scholarsmost notably in economics and sociology-have used the term praxeology to refer to the study of specific human practices which takes a pragmatic position on classical philosophical debates, while retaining the solidarity and inseparability of the action and reasoning as parts of such practice. According to an early proponent of the study of praxeology, the Austrian economist Ludwig von Mises (1949, 39),

... human action stems from the same source as human reasoning. Action and reason are congeneric and homogeneous; they may even be called two different aspects of the same thing.

We do not use or describe the theory of von Mises here, except for noting it as the first systematic use of the basic idea of studying praxeology. A related but at the same time very different notion of praxeology, which is essentially the one we use here, was introduced into the didactics of mathematics by Chevallard $(1999, \S 1.2)$, and has also been used in other fields (e.g. Rump \& Winsløw, to appear). Chevallard introduces his notion as follows (we explain it further below):

The anthropological theory of didactics considers that all human activity consists in accomplishing a task $t$ of a certain type $T$, using a certain technique $\tau$, explained by a technology $\theta$, which permits at the same time to think of it or to produce it, and which in turn is justifiable by a theory $\Theta$. In short, all human activity brings about an organization that one may denote $[T / \tau / \theta / \Theta]$ and that we call a praxeology, or praxeological organization. The word praxeology underlines the structure of the organization $[T / \tau / \theta /$ 
$\Theta]$ : the Greek praxis, which means 'practice', refers to the practical-technical (or practice) block $[T / \tau]$, while the Greek logos, which means 'reason' or 'reasoned discourse', refers to the technological-theoretical block $[\theta / \Theta]$. (Chevallard, 2002, 3; translated from French)

In this paper we shall not use Chevallard's formal notation (of which we have just shown the mere beginnings), but we retain the essential ideas of the model described above. We note that the practical block, consisting of type of task and technique, corresponds to what von Mises calls invariably 'ends and means' of human action. The theoretical block is then a more detailed model of what von Mises calls 'reason'. However, not only 'pure reason' but also affect and intuition may clearly influence the development and enacting of all four elements of a praxeology.

In broader terms, the task, the techniques, and the theoretical block of a praxeology correspond to answers to the questions 'what is to be done', 'how is it done', and the 'why is it done so', which may be asked about a given human practice. In an empirical study where we record the descriptions of those enacting the praxeology in question, we would have to interpret and to some extent accept the discourse (technology) they use; we return to this point in the section Methodology. At this point, we just note that in our study we use what we call a '3T model' of our object of study, consisting of tasks, techniques, and theory, which leaves the discourse used to describe these elements to be interpreted, but largely accepted by the observers.

To give a banal yet illustrative example of the original $4 \mathrm{~T}$ model $[\mathrm{T} / \tau /$ $\theta / \Theta]$, a type of task could be 'to fold a piece of paper' - something most of us have done a very large number of times and could do again without much thinking. A corresponding technique would be a certain sequence of movements involving both hands and some of their fingers. A technology would then be a more detailed explanation than the one provided here-'techno-logy' means logos of the technique-while a theory (which we can hardly imagine!) would justify just how the described actions permit one to achieve the folding of the paper.

As this example shows, many every-day praxeologies have weak or non-existing technology and theory. This is rarely the case for praxeologies related to mathematics or science task types, such as 'to calculate an integral' or 'to qualify remote sense data'. Whether or not the action is discursive, the possibility for humans to produce an articulate description and justification of a practice block is usually essential in the case of scientific (or otherwise learned) practice blocks.

In fact, it is in the context of school mathematics that most analyses of praxeologies in Chevallard's sense have been done. An important example is the study by Barbé, Bosch et al. (2005) where students' and 
teachers' practices related to limits of functions are analyzed in the context of the Spanish high school. These praxeologies, as it is to be expected in any disciplined field of knowledge, occur in coherent organizations rather than independent praxeologies. For example, to calculate the limit of a function at infinity, or to determine the limit of a function at a point, one may appeal to a common technology of 'algebra of limits' to justify the techniques used. Praxeologies sharing a common technology are said to form a local organization (in this case, a local mathematical organization). It may also be that the technologies of two praxeologies can themselves be justified within the same theoretical discourse. The praxeologies organized this way are said to form a regional organization. This, for instance, may be the case for the local mathematical organization concerned with computation of limits and the local mathematical organization concerned with determining whether a given limit exists (in fact the absence of such a regional mathematical organization in the curriculum of the Spanish high school was a main finding of the study mentioned above).

It is important to note here that praxeological organizations exist, are created and circulated within institutional frameworks, such as schools and universities. In the case of an institution of teaching, one finds not only organizations of disciplinary practice (e.g. mathematical or geographical organizations) but also didactical organizations enacted by teachers and students, where the generic aim of tasks is to appropriate (students) or to help appropriating (teachers) a given disciplinary organization. Teachers' and students' perceptions of these aims may well result in modifications of the disciplinary organizations enacted, at least temporarily.

In the study of the teaching of limits in the Spanish high school, the teacher tried to overcome the 'gap' between the two aforementioned local mathematical organizations by introducing certain auxiliary tasks and techniques, e.g. 'reading off the limit from the graph' or appealing to (unwarranted) continuity of the function. The overall conclusion of the authors is that institutional restrictions, mainly imposed by the curriculum, prevent the teacher from creating a coherent didactic organization so that instead he resorts to more or less independent 'themes' (Barbé et al., 2005).

Similar effects could conceivably arise in praxeologies of research where the aim is not only to acquire but also to develop a disciplinary organization. However, there are currently few studies done on concrete praxeologies of research, while we do have broader studies of individual research practices in major disciplines (e.g., Burton, 2004). 


\section{Model of the Interplay between Teaching and Research}

We now present our model for studying teaching, research and their interplay. It is firmly based on Chevallard's notion of praxeology (and organizations thereof). In order to save breath and especially to remind the reader that notions such as 'research organization' are used in a very specific sense here, the model is introduced together with certain symbolic shorthand similar to that used in related research literature (e.g., Barbé et al., 1999).

In order to study the interaction between praxeologies of university teaching and research within a scientific discipline $\mathrm{X}$ (where, in our case, $\mathrm{X}$ will be $\mathrm{M}=$ mathematics or $\mathrm{G}=$ geography) we shall consider scientific organizations $\mathrm{XO}$ in two wider praxeological contexts: that of research organizations (RO) and didactical organizations (DO). The tasks of XO are tasks directly related to the discipline, which together with corresponding techniques can be articulated and justified in 'X-theoretical' discourse. If we consider a particular professor of X, enacting simultaneously a RO and a DO, the XOs related to this $\mathrm{RO}$ and $\mathrm{DO}$ will typically be different, at least in scope. To distinguish them, the $\mathrm{XO}$ to which his research pertains will be denoted $\mathrm{XO}_{\mathrm{R}}$ while the $\mathrm{XO}$ he is teaching (and in which the students are supposed to engage) will be denoted $\mathrm{XO}_{\mathrm{D}}$. Our objective is now to study the nexus (cf. sec. 2) as the interaction of RO and DO and, more specifically, of $\mathrm{XO}_{\mathrm{R}}$ and $\mathrm{XO}_{\mathrm{D}}$, in the practice of university professors of $\mathrm{X}$, and in a more indirect way, to situate the consequences of this nexus for the actual and potential practices of students at the same institution. An illustration of these ideas is given in Figure 1.

It is important to note that both ROs and DOs contain praxeologies that do not belong to $\mathrm{XO}_{\mathrm{R}}$ and $\mathrm{XO}_{\mathrm{D}}$, respectively, even if it may be difficult to draw a sharp boundary between disciplinary and auxiliary tasks. For example, the calculation of an integral can be a task within a $\mathrm{MO}_{\mathrm{D}}$, as it

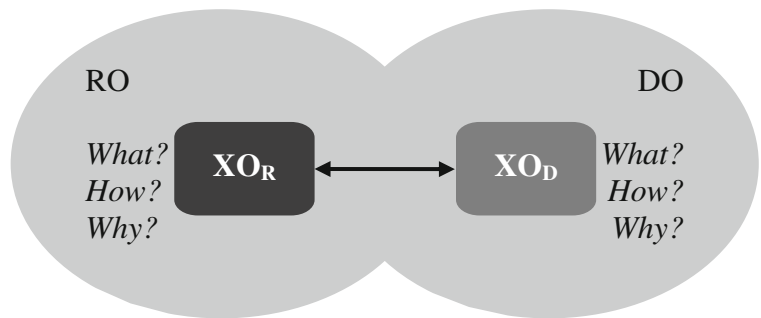

Figure 1. Schematic overview of our theoretical model of the TR-nexus, based on Chevallard's (2002) approach 
appeals to mathematical techniques and so on. The task of preparing a lecture on this belongs to the DO, but most of the techniques and reasons for the practices of lecturing would typically not be 'mathematical', even if the choice of techniques naturally depends on considerations about the knowledge to be presented. Similarly, a type of task involved in a RO can be to communicate a result to a co-researcher, but the techniques to do so as well as the rationales behind the technique adopted may depend only in part on the subject matter praxeology $\mathrm{XO}_{\mathrm{R}}$.

The main point of using the 3T-model described in the previous section, in order to describe the complex structure of the involved organizations of practice, is that we may distinguish certain crucial levels of the involved praxeologies: types of tasks, techniques, and theory (the latter meaning systematic justification or reasoning related to the technique). This also means that the interaction could arise among different levels: for instance, one might justify the choice to include certain task types and techniques in $\mathrm{XO}_{\mathrm{D}}$ by their importance within more advanced practices in $\mathrm{XO}_{\mathrm{R}}$. In this case, we would have a why question about teaching (DO-theory) answered rather explicitly by the practical level (tasks/techniques) of $\mathrm{XO}_{\mathrm{R}}$. It may also be that certain techniques from research $\left(\mathrm{XO}_{\mathrm{R}}\right)$ may be used to construct tasks for students $\left(\mathrm{XO}_{\mathrm{D}}\right)$ and thus contribute to DO-techniques. And so on. Of course, many combinations are possible for the interplay, but we shall distinguish three main types (cf. Winsløw \& Madsen, to appear):

- a minimal nexus consisting of the coexistence of RO- and DO-tasks within the duties of a professor, its distribution in a given segment of the professor's time, etc.

- an explicit nexus that involves theoretical elements (explicit reasons for the practice) of either the scientific discipline (XO-theory) or of its teaching (DO-theory).

- an implicit nexus in which tasks and techniques (e.g., of $\mathrm{XO}_{\mathrm{R}}$ and $\mathrm{XO}_{\mathrm{D}}$ ) are somehow related, straightforwardly or by analogy, but without an explicit articulation or justification of this relation in terms of corresponding theoretical blocks.

Notice that the two last categories correspond roughly (although not precisely) to Neumann's notions of tangible and intangible nexus (cf. section Background and Motivation) while the first is a restatement of our assumption that the same individual is teaching and doing research-we call this connection minimal as it may conceivably exist without further or deeper consequences for the two praxeologies. 


\section{Methodology}

This study is based on ten qualitative interviews with researchers at the Department of Mathematical Sciences and the Department of Geography and Geology both at the University of Copenhagen. Four interviews were with professors and six interviews with associate professors, all with extensive experience in teaching and research. The respondents were selected based on a strategy of covering as many research specialties as possible (including both theoretical and applied parts of the two disciplines). We also made sure they all had teaching at the undergraduate level at a regular basis (including mandatory courses). Most respondents also teach courses at the master level. All of them are internationally recognized researchers. All respondents were male: in the departments mentioned, there are no tenured female researchers in physical geography, and just three women out of 37 tenured mathematicians (one of the three was hired after the interviews took place).

\section{Interviewing}

The interviews were conducted in the first half of 2006. The respondents were asked to participate in an interview about 'possible relations between research and teaching'. All those contacted were willing to participate. If possible, the interviews were conducted in the respondent's office, in order to use the spatial aspect strategically to situate the interview in its social and cultural context and thereby enrich the explanations of the participants as described by Elwood and Martin (2000). As regards relative position in the interviews, we note that the interviewers (the authors) hold $\mathrm{PhDs}$ in the respective disciplines of the respondents and have completed considerable post-doctoral research in these disciplines (although clearly not in the specialty areas of each respondent).

The interviews lasted $1-1.5 \mathrm{~h}$ and were semi-structured. They centered on three distinct parts: research, teaching, and the relations between them, with a focus on the individual respondents' experience and perceptions from current practices. The questions were organized according to the study's theoretical framework. In the part on research, we asked the respondents to select a recent research project (part of a research organization, RO), and the questions dealt with the 'what', 'how', and 'why' of this activity-in particular the central $\mathrm{XO}_{\mathrm{R}}$. For instance, we asked them to describe the research process of the chosen research project from the beginning to the end, how they got the idea(s), how the work 
proceeded, and what where their tasks within the process. Along the same lines, the part on teaching focused on a recent undergraduate course taught by the respondent (the 'what' 'how', and 'why' of a didactical organization; $\mathrm{DO}$, with focus on a concrete $\mathrm{XO}_{\mathrm{D}}$ ). Here, we, for example, asked the respondents to explicate the students' activities (related to the subject matter) within the given course. These two parts then supported the discussion of the relationships between research and teaching, as references could be made to concrete instances of the respondents' current activities both by the respondent and by the interviewer.

\section{Data Handling}

All interviews were taped in agreement with the respondent and later transcribed in Transana-MU, version 2.12 (Woods and Fassnacht 2007). With this software, the transcripts were coded according to the theoretical framework as to whether it belonged to the 'what', 'how', or 'why' of the research practice (RO) or the 'what', 'how', or 'why' of the discussed teaching practice (DO). Further, the data were coded according to their pertaining to the central $\mathrm{XO}_{\mathrm{R}}$ or $\mathrm{XO}_{\mathrm{D}}$, the more general $\mathrm{RO}$ or $\mathrm{DO}$, or to the various relations between their praxeological levels. The coding was made by two researchers individually and compared afterwards. The reliability of the coding was high. As an example of the coding procedure, the following quotation is coded as theoretical level ('why') of the didactical organization (DO):

We do not even consider in advance what the perfect answer is, because we are not interested in the perfect answer. We want the students to consider what problems are involved in getting an answer

In the analysis, extracts were made on the relationships between research and teaching focusing on the differences between fields of mathematics and geography. The interviews were conducted in Danish and selected quotations were translated into English for use in this paper. This poses an obvious translation problem, given the informal nature of spoken language; we have chosen translations which are as close as possible in meaning, as opposed to more verbatim ones in case they would be meaningless in English. Respondents have been kept anonymous to the extent possible (that is, we cannot exclude that close colleagues might guess the origin of some of the quotes). The mathematicians were numbered $\mathrm{M} 1, \mathrm{M} 2, \ldots, \mathrm{M} 5$, the geographers $\mathrm{G} 1$, $\mathrm{G} 2, \ldots, \mathrm{G} 5$, and each quote is identified with one of these labels. 


\section{RESULTS}

In this section, we describe as concisely as possible our most salient observations from the material, quoting selectively from the interviews to illustrate our points.

\section{The Minimal Nexus}

Both mathematicians and geographers indicated an existence of a minimal nexus between research and teaching and all ten respondents agree that being a researcher is necessary in order to be able to teach the way they do. Some of the mathematicians, however, indicated that this relationship may not be 'visible' for the students:

Without my research I couldn't teach the way I do. It's completely excluded. I couldn't because you gain a very, it gives a deep understanding of what mathematics really is, when you have done research by yourself (M3).

It is very visible for me [the impact of my research on my teaching] but I do not think it is visible for the students, actually I don't believe it is (M2).

It was clearly, that the mathematician expressed much more explicitly problematic effects from the fact that their job involves both teaching and research than the geographers did. In particular most of the mathematicians point out conflicts of time and interest:

Consequently, it is clear that there is a clash of interests because you have two duties (M2).

There is a conflict of time and that I shall not downplay that... (M1).

Despite the constraint on research time induced by teaching, all mathematicians seemed to be rather fond of teaching, or at least to get some satisfaction from it.

Finally, most geographers and all of the mathematicians say that teaching is not necessary for doing research:

To be honest it [teaching] is not a necessity for research - it is a delightful extra benefit (G5).

You can ask yourself if it is strongly necessary-if you as researcher must have another job-that it necessarily must be teaching...personally it suits me very well especially because I feel that I can get thing forth and back between the to parts (M2). 


\section{The Implicit Nexus}

It turned out to be easier for all the interviewed researchers to reflect about techniques than about theory blocks in relation to creating links between research and teaching. At this level, the links between the practical blocks of $\mathrm{GO}_{\mathrm{D}}$ and $\mathrm{GO}_{\mathrm{R}}$ described by the geographers seem to be less distant than the links between the practical blocks of $\mathrm{MO}_{\mathrm{D}}$ and $\mathrm{MO}_{\mathrm{R}}$ as described by the mathematicians.

All respondents agree that as a researcher who is teaching, you are able to see what content (XOs) you need to bring into teaching, but there is a difference between mathematics and geography. In mathematics, a selection of contents has been made, often long ago, and the content is strictly determined by the curriculum:

I would say, however, that it [the teaching] is research-based in the sense that at a given time there has been a selection of topics and there has been a (for instance) it is not necessarily me who has selected the topics for the course but others have designed the course, I should then carry it out so to speak. But there are still some choices when you are doing the things in practice right? (M4).

For geographers, the choice of teaching contents is freer and is often linked to the professor's current research. This means they can use their own data and results from $\mathrm{GO}_{\mathrm{R}}$-practice as material to create $\mathrm{GO}_{\mathrm{D}}$-tasks, even at the undergraduate level:

Well, I give them the data and it is often...results of some of the projects that we have had and this set of data would be really good for this... (G5).

You have a temperature curve that shows an impact on another parameter, there is a relationship between radiation and temperature, that you have found in your research and that you bring in. In that way we get material in (G3).

Some have also been writing bachelor projects about it where there has been selected a section of data and - I get all data in and make the database and it is relatively easy to cut a series of data out which I think is relevant and could be an interesting way of presenting the problem for the student $(\mathrm{G} 2)$.

To the mathematicians, their work on constructing $\mathrm{MO}_{\mathrm{D}}$-tasks 'resembles' $\mathrm{MO}_{\mathrm{R}}$-practice in more subtle and indirect ways, e.g., by analogy, or by using similar cognitive processes:

But I will go so far as to say that I use the same part of the brain to make examination papers as I use to make research. That is, it is a little creative....also satisfying when you feel that you have made a good examination paper (M2). 
... the processes are much alike [RO-work and constructing project tasks for students] and maybe also that is why I think it is fun to make such assignments and actually I happen to use much time on calculations to see what you [implicitly, the students] can do (M5).

In relation to techniques there seems to be a focus in mathematics on techniques which, while needed in research, are still rather far from the more general techniques used in teaching. One mathematician experiences this as a problem:

In an ideal world, I would like to see [long silence] that the students learned the mathematical method ... we should give more weight to the working method [that of the $\mathrm{MO}_{\mathrm{R}}$, authors] rather than learning mathematics in a mechanical way (M3).

\section{The Explicit Nexus}

The explicit nexus appears in very limited ways among all respondents. In particular, we found little systematic reasoning about teaching practice or its relation to theoretical blocks of DO, and much reference to personal experience and traditions. Despite the limited explicit nexus, there seems to be a difference between the two disciplines in relation to the modalities of bringing research questions into teaching. While the geographers do take current research problems into their teaching (cf. the section The Implicit Nexus), the mathematicians tend not to see this as a possibility, or at least not at the undergraduate level. A few reasons for this were suggested, such as 'approachable mathematics is old':

No these models are necessarily so simple that it is something that has been studied in research 50 years ago (M5).

The problem with that is that you have, well, the bigger the course is the more need you have for control and guidance, and there is, you know, this about research, you never know where it ends (M2).

Instead, most of the mathematicians sometimes try to construct 'research like' student tasks (cf. the section. Relations Between Disciplinary Student Activity and Research Activity).

Both geographers and mathematicians mention that they sometimes try to justify or motivate elements of $\mathrm{XO}_{\mathrm{D}}$ by referring to their relation to research:

I choose this example among many others because if you can link it to reality [research] then I think it is more appetizing [for the students] (G1).

I know, I can tell them stories [emphasizes this word] about what you can use it for (M2). 
Finally, three of the mathematicians indicate that the more theoretical the subject is, the more difficult it is to integrate research in the teaching practice (cf. also the section Horizontal Versus Vertical Metaphor of the Discipline (XO)). Indeed, the applied mathematicians in our sample (M1 and M5) tend to support this and find it less difficult to integrate their research and teaching practice. The geographers did not say similar things about theoretical research and difficulties of linking it to teaching. However, the geographers all chose to talk about an applied-oriented research project in the interviews which might influence the fact that problems of linking theoretical issues to teaching didn't come up.

\section{Continuum or Separateness of Research and Teaching}

During the interviews the respondents were asked if they found that there exists an absolute difference between their activities in research and teaching, or if they saw it more like a continuum. The question was put in an open way, which is also reflected in the answers that deal both with the general research and didactical organizations (RO and $\mathrm{DO})$ and the more specific subject matter practices $\left(\mathrm{GO}_{\mathrm{R}}, \mathrm{GO}_{\mathrm{D}}\right.$ and $\left.\mathrm{MO}_{\mathrm{R}}, \mathrm{MO}_{\mathrm{D}}\right)$.

Among the geographers, there is a clear image of the continuum becoming more and more visible as the students' progress with their studies:

No I don't [see research and teaching as two different things]. If you are talking about a lecture at first year, yes then there is...but...from the undergraduate level it is a research collaboration you have with the students (G1).

It is completely fluid for me. As soon as you get to the master level it is fluid for me...it is very important for me that I go from being a teacher to a supervisor to be a colleague with my PhD-students (G2).

That [research and teaching] I think is very much a symbiosis...especially the people you get at the master level (G3).

At least three mathematicians (M1, M3, M5), and all the geographers, expressed clear adherence to the option of continuum. One mathematician (M4) said that to him, an absolute difference exists between research and teaching. Finally one (M2) said doing research and teaching are two fairly separate jobs to him, even if he sometimes had been lucky to combine them (mainly in the context of graduate student projects). Also among the three mathematicians opting for a continuum, we found some reservations and assertions which show that the two activities may often be rather separate:

There is clearly a continuum ..... where ... the two things clash is that what I research at the moment is not often what I am trying to get the students to do (M1). 
The general impression is indeed that the five mathematicians do not often' enact $\mathrm{MO}_{\mathrm{R}}$ and $\mathrm{MO}_{\mathrm{D}}$ as a continuous whole, as opposed to what we found with the geographers. One of the mathematicians points to a more general difference in the conditions for research and teaching:

...the demands that you face are very different in research and teaching. In research it is typical some very long termed goals you have and it is relatively easy to postpone them for a week or two.... when you are teaching then you can easily use all your time on it (M2).

This suggests an important difference between teaching tasks and research tasks: the first ones occur in rapid succession with firm deadlines, while research tasks may be postponed. Moreover, solving teaching tasks gives immediate results or even satisfaction, while research tasks are long termed goals. Research tasks may be perceived as 'harder' and the presence of short-term tasks can sometimes be pleasant excuses to postpone them (cf. also Halmos, 1985, 321f).

The respondents mainly talk about ways in which research activity may or may not contribute to teaching, but perceiving a continuum or not may also have to do with the degree to which teaching can inspire or even contribute to research. To the geographers, the relation is often quite symmetric:

But otherwise it is this kind of symbiosis where you get some ideas from your teaching practice and you try to implement it in your research (G1).

I have for instance taken my own data from an article into such a calculation exercise problem [for use in teaching]. And that is interesting, the things they get from it... I get a kind of feedback because sometimes you can calculate things in different ways and get different results. What is then the uncertainty and deviation in what I have calculated? (G2).

If you try to write a project proposal [research], it's almost similar to propose a new course in the way you also have to think what the line is, what's the goal, what would you like to have the students learn from it (G4).

To the mathematicians, the relationship is often more asymmetric. The possibility of a contribution from teaching to research is mentioned by the three mathematicians who opt for a continuum. However, when described by the respondents the contribution seems quite limited:

There is also an influence the other way, however, that is, from teaching to research, ehm, that can be, when you teach, you get to think, that is, when you must teach, you have to, you learn the material, it is the one who teaches who learn something... and there can be questions from the students which, oops, I hadn't though about that (M4). 
Ehm, but, unintentionally, the students in a way also help you to reflect on stuff,'cause there are always some good questions...but, ehm, to be honest, then, it is not a necessity for research, it's like such a nice extra bonus of teaching (M5).

The mathematician M4, who opts strictly for absolute difference, flatly rejects the idea that his students, and his teaching, could contribute to his research:

How long did it take me before I had an impression of what is going on in the research area that interests me? Well it took 5 years, after I had graduated.... You can't tell a bachelor student what it is about can you? It is an absurdity to demand it. I can tell you about it, I can give examples of it but to say that now the students should help me in my research that is absurd, that is not possible (M4).

\section{Relations between Disciplinary Student Activity and Research Activity}

How, then, does the students' activity (within DO) relate to research, according to our respondents? In what ways and to what degree are their activities within $\mathrm{XO}_{\mathrm{D}}$ close to the researchers' activity with $\mathrm{XO}_{\mathrm{R}}$ ? Here the differences between mathematics and geography come out even clearer. The geographers talk about students actually doing research, by being involved in processes based on scientific methods. For the mathematicians, there is normally a fundamental difference. The students research activity is characterized, at times, as being research-like, with some of the same characteristics as research practice (e.g., at the level of tasks, working with open questions); but it is often highlighted that it is not research as such, and it can not be, because the problem the students work on has been solved already, or because the students cannot be expected to solve real problems (at least not at the undergraduate level):

One thing is to solve a research question, it is clear that we [in fact, the students] don't do that .... but we try to give them an experience that is similar to the ones you have as a researcher....we give them relative open questions (M1).

I think that I can easily make assignments to the students that resemble a lot the research experience I have myself (M1).

However, when speaking of giving students tasks which present them with a high level of challenge, the mathematicians express concerns about getting the students frustrated by the fact that there is no immediate technique to apply, and often no obvious answer. Some of the geographers have similar concerns:

This is because I need to be absolutely certain that it is possible within the timeframe [discussing a student activity] ...I don't mind that the discussion is complicated but 
the calculation exercises problems should not end in frustrations due to uncertainties (G2).

But in general, the geographers tend to be more inclined to use open student tasks, like in the research process - for some of them the students' work can even be part of a genuine research work:

The bachelor project is a research project. There are two projects I have with four students at the moment. One of them solves a part of a research project I have in [a specific location] where we look at run-off measurements.....here the students participate with their project as a kind of research assistant in a part of the project that maybe one day becomes another article, because they contribute with a new layer of information to our knowledge (G1).

Interviewer: so they go through some of the same steps as you do when you are researching? Respondent: Yes they do. They must search for knowledge and they also need to go through that stepwise process from an idea - we have an idea and then we need to search if there is data for it and ....find data and then need to wonder about the results and ...the report of the results is just like a research paper (G5).

This difference also pertains to how early in the study the students are able to do research. The geographers see possibilities for the students to enact parts of $\mathrm{GO}_{\mathrm{R}}$ much earlier in the studies where some mathematician even questions if the students may do so during their masters' studies. This difference may be linked to the perception of the field as either vertical or horizontal as discussed in section Horizontal Versus Vertical Metaphor of the Discipline (XO). It can also be interpreted in terms of differences in the conditions for the broader RO-practices within the two disciplines, as elaborated and discussed in section Horizontal vs. Vertical Distributions of Participants' Roles in Research.

\section{Horizontal versus Vertical Metaphor of the Discipline (XO)}

The subject can be 'high' or 'wide', not that I say that if it is wide then it is not...less difficult or...that's not what I am saying, but there is a difference among things and there is a difference in how much time you need to work before you even understand the problem (M4).

This description illustrates well the perception of a discipline as either more vertical or more horizontal, in the following sense. By a vertical discipline we mean one in which extensive prerequisites are needed to access a modern $\mathrm{XO}_{\mathrm{R}}$ because techniques and theories are built up in cumulative ways; a horizontal discipline is one where different $\mathrm{XO}_{\mathrm{R}} \mathrm{S}$ live 
side by side, sometimes interacting, but not drawing on each other as strict prerequisites. Thus, in a vertical discipline, research typically means to produce or refine high-level techniques within (and based on) a sophisticated theoretical framework, and new research praxeologies will often base their tasks on the theory blocks of previous research organizations. In a horizontal discipline, it may be more common to apply existing techniques and theory to new types of tasks (or new contexts for existing task types, as in 'applied research') and to display a broad spectrum of different research organizations that are only marginally dependent on each other.

In regard to this distinction, the mathematicians mostly describe their research organizations $\left(\mathrm{MO}_{\mathrm{R}}\right)$ as vertical. The physical geographers mainly describe theirs (GOR) as horizontal, although vertical metaphors occur in one case related to mathematical prerequisites for a geography course. The mathematicians were more explicit about the vertical metaphor than the geographers about the horizontal one. Whether or not the metaphor is used as in the above citation, it seems from the interviews that this dichotomy of perceptions of one's research field has a profound effect on how the relationship between teaching and research is constructed and conceived in relation to the study of a variety of different, parallel $\mathrm{XO}_{\mathrm{D}} \mathrm{s}$ (horizontal) or as a succession of $\mathrm{XO}_{\mathrm{D}} \mathrm{S}$ which build successively upon each other (vertical; cf. Winsløw, to appear, for a detailed case study of such structures of $\left.\mathrm{MO}_{\mathrm{D}} \mathrm{s}\right)$. The vertical metaphor describes the education of students as a way of building stones that must be put on top of each other, some knowledge must be put before other knowledge in a certain order:

If you are going to build a skyscraper then you need concrete right? (M4).

It doesn't make sense that you start with the roof, then the house can't stand, it will fall apart. You need to give them [the students] a proper base, proper foundation, and then you can start to build sensibly up through the system. Then they have an understanding of that this is becoming a nice and connected house when you finish (G3).

This means that the teaching practice is subordinated to a range of rigid restrictions as regards the sequence of topics; this is sometimes linked to the perception of an ever lowering level among the students. By contrast, a horizontal metaphor is present in the description, by a mathematician, of an 'ideal' $\mathrm{MO}_{\mathrm{D}}$, which he cannot realize due to the constraints of a vertical syllabus:

Of course they need to have some concrete ideas, definitions to work from but I would imagine that ...they have a bare field in front of them and we have a beginning 
to a path, and then they have to pave it.... the barrier is that there is a concrete syllabus, they have to learn that and that, and the other method is time demanding.... in physics, they require, they have to learn this particular theorem.... ... In other courses I can see, that we build on this and that course and here they have learnt this and that.. So you see this [idea] does not work in our system (M3).

The geographers do not actually describe the structure of their study program $\mathrm{GO}_{\mathrm{D}}$ as horizontal, but looking at their descriptions of teaching practice (and at the program itself) it is justified to consider it to be so. It also appears that the horizontal structure of $\mathrm{GO}_{\mathrm{D}}$ almost imposes the challenge of integrating $\mathrm{GO}_{\mathrm{R}}$ into it, whereas the vertical structure of $\mathrm{MO}_{\mathrm{D}}$ acts as a justification (or at least explanation) why it is difficult to integrate elements of $\mathrm{MO}_{\mathrm{R}}$ in it.

\section{Horizontal vs. Vertical Distributions of Participants' Roles in Research}

The interviews show clear differences between mathematics and physical geography with respect to the way research and teaching are organized in terms of the roles of the participants. This seems to influence the perception and degree of interaction between $\mathrm{XO}_{\mathrm{R}}$ and $\mathrm{XO}_{\mathrm{D}}$, and in particular the inclusion of students into $\mathrm{XO}_{\mathrm{R}}$ practices. The difference can be illustrated by the following two stories of 'a bus trip in Poland' and 'observations of heat development in Svalbard'.

A bus trip in Poland:

It started so to speak on a bus trip in Poland, we were on our way to a conference and a third mathematician had a casual remark concerning an idea... it is 7-8 years ago, I think, and we saved the idea and took it up later (M3).

The work referred to in this quote was conducted with a researcher from another European university. It has been established through a more or less fortuitous conversation with a third colleague and subsequently developed through meetings and emails where an emerging manuscript was worked on while being sent back and forth. The two researchers had complementing areas of expertise for the concrete research problem and have taken turns in writing the organically evolving manuscript. In this sense one may say that the distribution of roles in the research activity (RO) is horizontal. The fact (explained earlier) that the mathematical organization is seen as vertical means that the RO tends to be exclusive (in particular, with respect to students). 
Heat development in Svalbard:

The idea stems from the fact that I teach at the university at Svalbard .... what triggers me is that the heap seems warm at winter. Measurements show that the heap is warm and that makes me set up the working hypothesis that what has been believed up to now - that the summertime is the most important period for studying the strain on plants by heavy metal - is false; it's the wintertime (G2).

Two colleagues, five masters students (some of them started with smaller assignments just after their bachelor degree), and one $\mathrm{PhD}$-student have been involved in the research project. For the leading researcher, work has been devoted to organising the field work periods, securing that measurements where taken continuously, organizing meetings, apply for research permissions and funding, and correspond with relevant authorities. Another part of the job has been to organise the data processing with students and colleagues. Many of the students have conducted small parts of the data processing in their master thesis project. The researcher indicates that this means that data is much more ready to publish due to the work of the students. Many of the students will subsequently be first authors on the resulting refereed articles.

In this last way of organizing the research activity within geography, the researcher acts as project leader with organizational and main responsibilities for the data collection and data processing periods. Some parts - including routine tasks - may be delegated to assistants. In this sense the distribution of roles in the research activity is vertical.

What are the consequences of these differences between the two disciplines? As for the mathematicians' horizontal enactment of the heuristic writing process within a research project, it appears that very little space is available for non-specialist participation. This in part is linked to the vertical structure of the $\mathrm{MO}_{\mathrm{R}}$, as already mentioned. But even with regard to advanced students or other specialists, an obstacle may be the risks of revealing unpublished ideas to others:

You could imagine that you continually told [students] for instance when you were working on a research project, what was going on and maybe you could include the best students in it. A kind of professional induction, yes that could be good but it demands also - there is prestige involved in research - so it demands that you must give away domain to other people (M3).

This remark also suggests a more fundamental difference between mathematics and an empirical science like physical geography, which is not mentioned in the interviews: in mathematics, a problem can be solved definitively, while in physical geography, one may always get better data 
or more precise models. This might explain why no geographers mention a similar need for confidentiality of results.

For the geographers due to the vertical structure of the research activity the students are at times important co agents in research, due to the need for data collection, albeit at a different level of enactment:

It is a research partnership you have with your undergraduate students...it is in principle a kind of professional induction...the students participate with their project as a kind of research assistant (G1).

I would suffer if the master thesis is reduced to 6 months compared to the 12 months we have now ...I would not be able to really use them [the students]; they do not reach the level where they actually start to do research (G2).

To combine these observations with those in the section Horizontal Versus Vertical Metaphor of the Discipline (XO), we may say that the vertical discipline organization of mathematics (with $\mathrm{MO}_{\mathrm{R}}$ well above $\mathrm{MO}_{\mathrm{D}}$ ) goes with horizontal structures of research collaborations (role distribution in RO) and this could explain the difficulty for students to enter this activity. Geography is a more horizontal discipline (with $\mathrm{GO}_{\mathrm{R}}$ often integrated into $\mathrm{GO}_{\mathrm{D}}$ ) but there is a more vertical role distribution in the research process. It seems much easier and even sometimes necessary to include students in these activities.

\section{ConClusions}

The theoretical framework from the section Theoretical Framework enabled us to design, analyze, and compare two sets of interviews which aimed to shed light on the relations between teaching and research in mathematics and physical geography. We found significant differences in how the respondents from the two disciplines described and assessed this relation. Above all, while $\mathrm{GO}_{\mathrm{R}}$ practices are often and smoothly integrated into $\mathrm{GO}_{\mathrm{D}}$ even at undergraduate level, $\mathrm{MO}_{\mathrm{D}}$ may at best be similar to $\mathrm{MO}_{\mathrm{R}}$, at least at the undergraduate level. Through a careful analysis of horizontal and vertical metaphors in the respondents' descriptions, we also found some possible causes for these differences. One is linked to the perceptions of the involved disciplines (vertical mathematics, physical geography more horizontal). The vertical internal structure of mathematical organizations seems to pose considerable obstacles to a more direct integration of $\mathrm{MO}_{\mathrm{R}}$ into $\mathrm{MO}_{\mathrm{D}}$, at least to the extent it was found in the context of physical geography. Curiously, this 
effect seems to be amplified by the ways roles are distributed in teaching and research (horizontally in mathematics, more vertically in geography): it is easier to have students act as assistants (with a gradual convergence towards partnership, as in geography) than as partners (as in a mathematical research project).

Although we have only been able to outline the most striking ones here, the differences we found suggest that, indeed, the relation between teaching and research depends in crucial ways on disciplinary specificities. At an institutional level, it should be known and acknowledged that the potentials for bringing research into teaching may consequently differ significantly from one discipline to another. This does clearly not mean that one should just accept the claims of some mathematicians that it is impossible to let students take part in 'real' research-indeed we found some of them describe cases where they had succeeded to do so. It seems plausible that some of the potentials in this direction could be used more fully by creating less rigid curricula. But one must also acknowledge that the character and importance of the challenges for achieving a more synergetic relation may depend on the discipline and that these challenges may accordingly have to be addressed within each discipline.

Official decrees are, in themselves, of little help here, even if there could be very good global reasons for a university to strive for more direct interactions between teaching and research. Instead, one must pursue this goal through research based development projects within each discipline - sometimes called 'didactical engineering' (cf. e.g., Artigue, 1994; Rump \& Winsløw, to appear). Ideally it involves science researchers in design oriented research on science teaching.

\section{REFERENCES}

Artigue, M. (1994). Didactical engineering as a framework for the conception of teaching products. In R. Biehler et al (Ed.), Didactics of Mathematics as a scientific discipline (pp. 27-39. ) Dordrecht: Kluwer.

Barbé, J., Bosch, M., Espinoza, L. \& Gascón, J. (2005). Didactic restrictions on teachers practice - the case of limits of functions at Spanish high schools. Educational Studies in Mathematics, 59(1-3), 235-268.

Brew, A. (1999). Research and teaching: Changing relationships in a changing context. Studies in Higher Education, 24, 291-301.

Burton, L. (2004). Mathematicians as enquirers. Kluwer: Dordrecht.

Chevallard, Y. (1999). L'analyse des pratiques enseignantes en théorie anthropologique du didactique. Recherches en Didactique des Mathématiques, 19(2), 221-265. 
Chevallard, Y. (2002). Organiser l'étude 3. Écologie \& régulation. In J.L. Dorier et al (Ed.), Actes de la $11^{e}$ école de didactique des mathématiques. Grenoble: La Pensée Sauvage. Elen, J., Lindblom-Ylänne, S. \& Clement, M. (2007). Faculty development in researchintensive universities: The role of academics' conceptions on the relationship between research and teaching. International Journal for Academic Development, 12(2), $123-139$.

Elton, L. (1986). Research and teaching: symbiosis or conflict? Higher Education, 15, 299-304.

Elton, L. (2001). Research and Teaching: conditions for a positive link. Teaching in Higher Education, 6, 43-56.

Elwood, S.A. \& Martin, D.G. (2000). Placing Interviews: Location and Scales of Power in Qualitative Research. Professional Geographer, 52, 649-657.

Halmos, P.R. (1985). I want to be a mathematician: an automathography. New York: Springer-Verlag.

Hattie, J. \& Marsh, H.W. (1996). The relationship between teaching and research: a metaanalysis. Review of Educational Research, 66(4), 507-544.

von Mises, L. (1949). Human Action. A treatise on economics. New Haven: Yale University Press.

Mora, J.-G. (2001). Governance and management in the new university. Tertiary Education and Management, 7, 95-110.

Neumann, R. (1992). Perceptions of the teaching-research nexus: a framework for analysis. Higher Education, 23, 159-171.

Ramsden, P. \& Moses, I. (1992). Associations between research and teaching in Australian higher education. Higher Education, 23, 273-295.

Rump, C. \& Winsløw, C. (to appear). The role and means for tertiary didactics in a faculty of science. In O. Skovsmose et al. (Eds.), University science and mathematics education. Challenges and possibilities.

Winsløw, C. (to appear). Transformer la théorie en tâches: la transition du concret à l'abstrait en analyse réelle. In A. Rouchier (Ed.), Actes de la XIIIème école d'été en didactique des mathématiques. Grenoble: La Pensée Sauvage.

Winsløw, C. \& Madsen, L. (to appear). The interplay between research and teaching from the perspective of mathematicians. Proceedings of the 5th congress of European research in mathematics education.

Woods, D. \& Fassnacht, C. (2007). Transana-MU v2.12. http://www.transana.org. Madison, WI: The Board of Regents of the University of Wisconsin System.

Department of Science Education,

University of Copenhagen,

Universitetsparken 15, 2100 Copenhagen, Denmark

E-mail:winslow@ind.ku.dk 